\title{
Utility approach for multi target streamlining of process parameters in wire EDM
}

\author{
A. Muniappan*, M. Ajithkumar, V. Jayakumar, C. Thiagarajan and M. Sreenivasulu \\ Department of Mechanical Engineering, Saveetha School of Engineering, Saveetha Institute of Medical and Technical Sciences, \\ Chennai, Tamil Nadu, India.
}

\begin{abstract}
This paper depicts the improvement of multireaction enhancement system utilizing utility technique to foresee and select the ideal setting of machining parameters in wire electro-release machining (WEDM) process. Investigations were arranged utilizing Taguchi's L27 orthogonal exhibit. A wide range of Wire EDM control variables such as pulse on time duration, pulse off time duration, servo voltage along with wire feed rate were judged for investigation. Multi reaction enhancement was performed for both cutting pace (CS) and surface unpleasantness (SR) utilizing utility idea to discover the ideal procedure parameter setting. The level of essentialness of the machining parameters for their impact on the CS and SR were controlled by utilizing investigation of fluctuation (ANOVA). In present study utility approach method used to optimize the process parameter in wire EDM of magnesium Al6061/SiC/Graphite hybrid composite with zinc covered brass wire electrode. The approach depicted here is relied upon to be profoundly useful to assembling enterprises, and furthermore different territories, for example, aviation, car and apparatus making businesses. The parameters corresponding to experiment run number 7 are pulse on time 108 units (Level 1), pulse off time 60 units (Level 3), peak current 230 units (Level 3), gap set voltage 60 units (Level 3 ), wire feed 3 units (Level 1) and wire tension 4 units (Level 1) are the best combination to achieve better surface roughness and cutting speed.
\end{abstract}

Keywords. WEDM, Utility approach, Taguchi method, kerf width \& surface roughness

\section{Introduction}

Composite materials had grown rapidly over recent few decades to encompass metal matrix composites, ceramic composites and polymer matrix composites. Metal grid composites have pulled in significant consideration because of their capacity to give an extensive variety of microstructures \& properties (Sharma 2000). The underlying philosophy of metal composite design is that an continuous metallic matrix, with its ductility and formability, is combined with the stiffness and load withstanding property of a ceramic or refractory reinforcements to produce material with superior properties [1]. Metal Composites possess good properties over metals alloys with high specific strengths, better properties of metal composite at elevated high temperatures, minimum thermal expansion, very good wear resistance \& high structural strength. These properties are predominantly suited to application in an automotive, aerospace and electronic sectors [2],[3].

Manufacturing sector is growing rapidly by accommodating technology modernization. The mechanism for machining hard reinforced materials, intricate shapes and contours which are very difficult to cut by conventional methods which created many unconventional methods. $\mathrm{CNC}$ wire cut machine was developed in the year 1969. WEDM which involves moving very thin wire electrode continuously. Wire electrode materials such as brass and zinc coated brass wire of diameter ranges from $0.05-0.35$ are widely

* Corresponding author: inspire.munish $@$ gmail.com applied in industry. The gap between work and wire electrode is generally ranges from $0.025 \mathrm{~mm}$ to $0.050 \mathrm{~mm}$ and is continuously maintained by a computer controlled coordinating system. To achieve better surface quality on the tool as well as in the component, optimum process parameter setting is a very important factor. Machining control parameters are optimized by using different methods for the improvement of the quality. Taguchi method which is widely applied mainly experimental design in manufacturing application. It allows the optimization of parameters in machining by turning, milling, Electro Discharge Machining, wire cut EDM, welding, grinding etc. The optimization is achieved with lesser number of experiments by this overall cost and time is saved.

\section{Materials and method}

\subsection{Preparation of hybrid composite}

In this investigation, the hybrid Aluminum $\mathrm{MMC}$ has been fabricated by stir casting process. The crossover composite comprises of $10 \mathrm{wt} \% \mathrm{SiC}$ and $5 \mathrm{wt} \%$ Graphite particulates in metal lattice Al6061 compound. The Al combination of $6 \times x x$ arrangement is having the capacity to be used in aviation and car ventures in light of its high quality to-weight proportion and great protection from consumption. Fortifications $\mathrm{SiC}$ and graphite in particulate frame are utilized to fabricate the hybrid composite. The easiest and the most savvy technique for fluid state creation is stir casting [19]. 


\subsection{Machining parameters and response}

Machining process parameters in WEDM, Pulse on time, Pulse off time, current, gap voltage, wire speed and wire tension were considered as input parameters. Responses SR and kerf width were measured after machining for investigation. The scopes of these procedure parameters were chosen on the premise of the pilot tests. The levels of different parameters and its assignments are exhibited in Table 2.

Table 1. Process parameters and their levels

\begin{tabular}{ccccc}
\hline Symbol & $\begin{array}{c}\text { Process } \\
\text { parameter }\end{array}$ & Level 1 & $\begin{array}{c}\text { Level } \\
\mathbf{2}\end{array}$ & $\begin{array}{c}\text { Level } \\
\mathbf{3}\end{array}$ \\
\hline A & Pulse on time & 108 & 117 & 126 \\
B & Pulse off time & 40 & 50 & 60 \\
C & Pulse current & 90 & 160 & 230 \\
D & Gap set Voltage & 10 & 30 & 50 \\
E & Wire drum speed & 3 & 4 & 5 \\
F & Wire tension & 4 & 8 & 12 \\
\hline
\end{tabular}

\subsection{Experimental design using Taguchi method}

Taguchi strategy is a proficient apparatus for the outline of a great assembling framework. It also effectively solves some complex problems in manufacturing (Roy 1990).It is a strategy in view of OA tests, which give much decreased change to the try different things with ideal setting of process control parameters. The six control parameters, that is, pulse on time (A), pulse off time (B), top current (C), Gap set voltage (D), wire drum speed (E) and wire tension(F) at three levels were chosen in this examination. The tests were finished by Table 3 . This table just speaks to specific level of the different elements of the procedure at which the examinations would be directed. Kerf width ought to be as least as conceivable in the WEDM procedure. Kerf width is an imperative component of the laser cutting procedure that gives the benefit of this innovation contrasted with different strategies for form cutting.

\subsection{Utility approach method}

A client assesses an item on various different quality attributes. To be ready to settle on an objective decision, these assessments on various attributes ought to be consolidated to give a composite list. Such a composite record speaks to the utility of a item. The general utility of an item measures the convenience of that item according to the evaluator. The utility of an item on a specific trademark measures the convenience of that specific normal for the item. The general utility of an item is the total of utilities of each of the quality attributes. Along these lines if $x i$ is the measure of adequacy of the trait (trademark) I and there are $n$ properties assessing the result space, at that point the joint utility capacity can be communicated as (Derek, 1982) :

$U\left(x_{1}, x_{2} \ldots x_{n}\right)=f\left[U_{1}\left(x_{1}\right), U_{2}\left(x_{2}\right), \ldots, U_{n}\left(x_{n}\right)\right]$
In linear case, the function becomes

$U\left(x_{1}, x_{2}, \ldots, x_{n}\right)=\sum_{i=\mathbf{1}}^{n} W i U(x i)$

where $W i$ is the weight age assigned to the attribute $i$ and the sum of the weightings for all attributes is equal to 1 . If the composite measure (the overall utility) is maximized the quality characteristics considered for evaluation of utility will automatically be optimized (maximized or minimized whatsoever the case may be).

\subsection{Experimental set up}

Analyses were led on Electronica Sprint cut (ElectraElplus 40A Dlx) CNC wire electrical release machine to think about the surface harshness and kerf width influenced by the machining parameters at various levels. WEDM is a start disintegration process. The flashes are produced between the work piece and the wire terminal. The dielectric liquid is ceaselessly encouraged into the machining zone with required weight. The material is getting expelled by a progression of discrete sparkles occurring at the zone to be machined through electro-warm system. Test set up of the wire electrical release machine is appeared in Figure 2.

Amid machining process little hole kept up between the work and wire material. The machined particles were flushed away by the persistent stream of the dielectric liquid. The wire is held by a stick direct at the upper and lower parts of the work piece. The work example measure utilized as a part of this examination is $95 \times 80$ x $8 \mathrm{~mm}$ rectangular plate. Zinc covered metal cathode wire of $0.25 \mathrm{~mm}$ width was utilized as a part of this investigation. Deionized water was utilized as dielectric liquid at room temperature. In the wake of machining, the examples were cleaned with acid after machining. The kerf was measured utilizing profile projector measuring framework. The kerf esteems were measured at six spots spread over the whole length of cut. The kerf esteems utilized as a part of this examination are the numerical normal of three estimations produced using the example in each cut.

\subsection{Weight Criteria Calculation using SDY Concept}

Standard deviation is connected to this examination for unprejudiced assignment of weights. The significance of weights in illuminating Multi-Criteria Decision Making (MCDM) issues can't be over stressed. To decide the standard deviation, the range institutionalization was finished utilizing Equation (1) to change diverse scales and units among different criteria into regular quantifiable units so as to figure their weights.

$$
X_{i j}^{\prime}=\frac{X_{i j}-\min _{1<j<n} X_{i j}}{\max _{1<j<n} X_{i j}-\min _{1<j<n} X_{i j}}
$$


where $\max X_{i j}$, min $X_{i j}$ are the maximum and minimum values of the criterion $(j)$ respectively. The standard deviation $(S D V)$ is calculated for every criterion using equation (2) given below.

$$
S D V_{j}=\sqrt{\frac{1}{m} \sum_{i=1}^{m}\left(X_{i j}-\overline{X_{j}^{\prime}}\right)^{2}}
$$

where $X j^{\prime}$ is the mean of the values of the $j^{\text {th }}$ criterion after normalization and $j=1,2 \ldots n$. After calculating for $S D V$ for all criteria, the next step is to determine the weights, $W_{j}$ of all the criteria considered.

$$
W_{j}=\frac{S D V_{J}}{\sum_{j=1}^{n} S D V_{J}}
$$

where $j=1,2, \ldots n$.

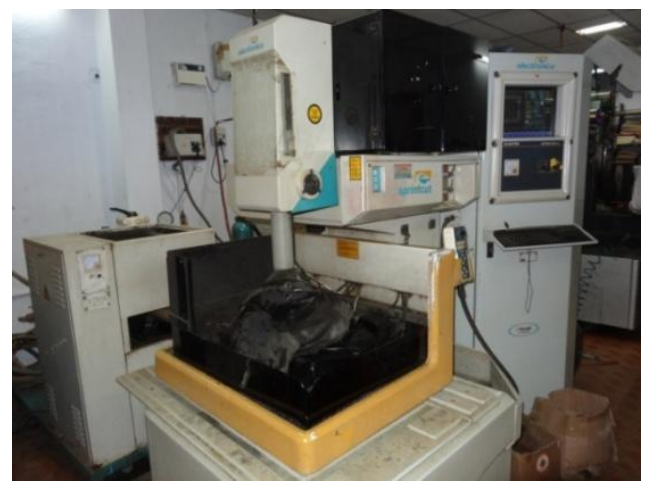

Fig. 1 WEDM experimental set up (Electronica Sprint cut)

\subsection{Methodology}

A preference scale for each quality characteristic is constructed. To determine the utility value for a number of quality characteristics later these scales are weighted to obtain a composite number (overall utility). The weighting is done to satisfy the test of indifference on the various quality characteristics. The preference scale should be a logarithmic one (Gupta and Murthy 1980). The minimum acceptable quality level for each quality characteristic is set out at 0 preference number and the best available quality is assigned a preference number of 9. If a $\log$ scale is chosen the preference number $(P i)$ is given by (Gupta and Murthy, 1980).

$$
\mathrm{P}_{\mathrm{i}}=\mathrm{A} \log \left(\mathrm{X}_{\mathrm{i}} / \mathrm{X}^{\prime}{ }_{\mathrm{i}}\right)
$$

where $\mathrm{X}_{i}=$ any value of quality characteristic or attribute i; $X_{i}^{\prime}=$ minimum acceptable value of quality characteristic or attribute I; and $A=$ a constant. At optimum value $\left(\mathrm{X}^{*}\right)$ of attribute i, $P i=9$. So

$$
\mathrm{A}=9 / \log \left(\mathrm{X}^{*} / \mathrm{X}_{\mathrm{i}}^{\prime}\right)
$$

The next step is to assign weights or relative importance to the quality characteristics. This assignment is subjective and based on experience. Moreover, it depends on the end use of the product or it may depend on the customer's requirements. The weightage should be assigned such that the following condition is satisfied:

$$
\sum_{i=1}^{n} W i=1
$$

The overall utility can be calculated as:

$$
U j=\sum_{i=1}^{n} W i P i
$$

where $j=$ product index.

\section{Results and discussion}

\subsection{Result analysis}

Table 5 shows the square of $\mathrm{Xi}$, normalized matrix for $\mathrm{Xi}$ and rank calculated by MOORA method. The normalized SR \& $\mathrm{KW}$ are multiplied with their corresponding weights. These values are listed in the table 6. The parameters, higher the better 9maximum) and smaller the better (minimum) respectively added for rank calculation. The surface roughness observed in the experiment is in the range of from 2.252 to 4.256 . Similarly the kerf width observed in the experiment is in the range of from 292 to 327 . From these observations, experiment number 7 has the best rank. The parameters corresponding to experiment run number 7 are pulse on time 108 units (Level1), pulse off time 60 units(Level3), peak current 230 units (Level3), gap set voltage 60 units (Level3), wire feed 3 units (Level1) and wire tension 4 units (Level1).

\subsection{Predicted optimum value of responses}

Mean of each response for each level of factor is shown in Table 3. The average of the $\mathrm{S} / \mathrm{N}$ ratio of the responses $\mathrm{SR}$ and KW for each level of each factor is shown in Table 4. Regardless of the category of the performance characteristics, a greater $\mathrm{S} / \mathrm{N}$ value corresponds to a better performance. Therefore, the optimal level of the machining parameters is the level with the greatest $\mathrm{S} / \mathrm{N}$ value. From Table 3 and Table 4 based on the analysis of means and $\mathrm{S} / \mathrm{N}$ ratios, the optimal machining parameter levels are $A_{1} B_{3} C_{1} D_{2} E_{1} F_{1} \& A_{1} B_{1} C_{3} D_{2} E_{1} F_{3}$ for $S R$ and $\mathrm{KW}$, respectively. The optimal level of each machining parameter is bolded in Table5.The predicted optimal value of each response characteristics can be determined using Minitab software version 18. The values are $2.0754 \mathrm{um}(\mathrm{SR})$ and $0.2858 \mathrm{~mm}(\mathrm{KW})$ respectively.

\subsection{Preference number calculation}

After obtaining the optimum value, a preference scale is constructed for each response. The preference scale should be a logarithmic one [15]. Zero is the preference number of the minimum acceptable quality level and 9 is the preference number of the best available quality level for each response. For the log scale the preference number (P?) is calculated by using Eqs. (4) and (5). 
Predicted optimum value of SR $\left(\mathrm{x}_{\mathrm{SR}}\right)=2.0754 \mathrm{um}$

Minimum acceptable value of SR $\left(\mathrm{X}_{\mathrm{j}}\right)=4.257 \mathrm{um}$

$\mathrm{P}_{\mathrm{SR}}=-28.85 \log \left(\mathrm{x}_{\mathrm{sr}} / 4.257\right)$

Predicted optimum value of $\mathrm{KW}\left(\mathrm{x}_{\mathrm{KW}}\right)=0.2858 \mathrm{~mm}$

Minimum acceptable value of $\mathrm{KW}\left(\mathrm{X}_{\mathrm{j}}\right)=0.327 \mathrm{~mm}$

$\mathrm{P}_{\mathrm{KW}}=-154.11 \log \left(\mathrm{x}_{\mathrm{KW}} / 0.327\right)$

Table 2. Surface roughness and Kerf width

\begin{tabular}{|c|c|c|c|c|c|c|c|c|}
\hline Ex.No. & $\begin{array}{l}\text { Pulse } \\
\text { on } \\
\text { Time }\end{array}$ & $\begin{array}{c}\text { Pulse } \\
\text { off } \\
\text { Time }\end{array}$ & $\begin{array}{c}\text { Peak } \\
\text { Current }\end{array}$ & $\begin{array}{c}\text { Gap } \\
\text { set } \\
\text { voltage }\end{array}$ & $\begin{array}{l}\text { Wire } \\
\text { Feed T }\end{array}$ & $\begin{array}{c}\text { Wire } \\
\text { Tension }\end{array}$ & $\begin{array}{c}\text { Surface } \\
\text { Roughness } \\
(\mu \mathrm{m})\end{array}$ & $\begin{array}{c}\text { kerf } \\
\text { width(mm) }\end{array}$ \\
\hline 1 & 108 & 40 & 90 & 10 & 3 & 4 & 2.605 & .302 \\
\hline 2 & 108 & 40 & 90 & 10 & 4 & 8 & 2.82 & .300 \\
\hline 3 & 108 & 40 & 90 & 10 & 5 & 12 & 3.185 & .292 \\
\hline 4 & 108 & 50 & 160 & 30 & 3 & 4 & 2.555 & .304 \\
\hline 5 & 108 & 50 & 160 & 30 & 4 & 8 & 2.625 & .300 \\
\hline 6 & 108 & 50 & 160 & 30 & 5 & 12 & 2.985 & .301 \\
\hline 7 & 108 & 60 & 230 & 50 & 3 & 4 & 2.52 & .302 \\
\hline 8 & 108 & 60 & 230 & 50 & 4 & 8 & 2.965 & .303 \\
\hline 9 & 108 & 60 & 230 & 50 & 5 & 12 & 3.115 & 297 \\
\hline 10 & 117 & 40 & 160 & 50 & 3 & 8 & 3.625 & .303 \\
\hline 11 & 117 & 40 & 160 & 50 & 4 & 12 & 3.48 & .309 \\
\hline 12 & 117 & 40 & 160 & 50 & 5 & 4 & 3.475 & .314 \\
\hline 13 & 117 & 50 & 230 & 10 & 3 & 8 & 3.57 & .317 \\
\hline 14 & 117 & 50 & 230 & 10 & 4 & 12 & 3.59 & .313 \\
\hline 15 & 117 & 50 & 230 & 10 & 5 & 4 & 3.975 & .322 \\
\hline 16 & 117 & 60 & 90 & 30 & 3 & 8 & 2.7 & .317 \\
\hline 17 & 117 & 60 & 90 & 30 & 4 & 12 & 3.125 & .313 \\
\hline 18 & 117 & 60 & 90 & 30 & 5 & 4 & 2.57 & .327 \\
\hline 19 & 126 & 40 & 230 & 30 & 3 & 12 & 3.515 & .302 \\
\hline 20 & 126 & 40 & 230 & 30 & 4 & 4 & 3.725 & .317 \\
\hline 21 & 126 & 40 & 230 & 30 & 5 & 8 & 3.81 & .302 \\
\hline 22 & 126 & 50 & 90 & 50 & 3 & 12 & 3.67 & .310 \\
\hline 23 & 126 & 50 & 90 & 50 & 4 & 4 & 3.32 & .324 \\
\hline 24 & 126 & 50 & 90 & 50 & 5 & 8 & 3.47 & .322 \\
\hline 25 & 126 & 60 & 160 & 10 & 3 & 12 & 4.125 & .316 \\
\hline 26 & 126 & 60 & 160 & 10 & 4 & 4 & 4.256 & .325 \\
\hline 27 & 126 & 60 & 160 & 10 & 5 & 8 & 4.11 & .318 \\
\hline
\end{tabular}

Table 3. Predicted levels of process parameters

\begin{tabular}{lcc}
\hline \multicolumn{1}{c}{ Parameters } & SR & KW \\
\hline Pulse off time & 60 & 40 \\
Current & 90 & 230 \\
Gap voltage & 30 & 30 \\
wire speed & 3 & 3 \\
Wire tension & 4 & 12 \\
\hline
\end{tabular}

Table 4. Preference number of individual responses

\begin{tabular}{ccccccccc}
\hline Ex.No. & $\begin{array}{c}\text { Pulse } \\
\text { on } \\
\text { Time }\end{array}$ & $\begin{array}{c}\text { Pulse } \\
\text { off } \\
\text { Time }\end{array}$ & $\begin{array}{c}\text { Peak } \\
\text { Current }\end{array}$ & $\begin{array}{c}\text { Gap } \\
\text { set } \\
\text { voltage }\end{array}$ & $\begin{array}{c}\text { Wire } \\
\text { Feed }\end{array}$ & $\begin{array}{c}\text { Wire } \\
\text { Tension }\end{array}$ & SR & $\begin{array}{c}\text { kerf } \\
\text { width }\end{array}$ \\
\hline 1 & 108 & 40 & 90 & 10 & 3 & 4 & 6.154 & 5.527
\end{tabular}

\begin{tabular}{|c|c|c|c|c|c|c|c|c|}
\hline 2 & 108 & 40 & 90 & 10 & 4 & 8 & 5.160 & 5.972 \\
\hline 3 & 108 & 40 & 90 & 10 & 5 & 12 & 3.635 & 7.781 \\
\hline 4 & 108 & 50 & 160 & 30 & 3 & 4 & 6.396 & 5.086 \\
\hline 5 & 108 & 50 & 160 & 30 & 4 & 8 & 6.058 & 5.972 \\
\hline 6 & 108 & 50 & 160 & 30 & 5 & 12 & 4.447 & 5.749 \\
\hline 7 & 108 & 60 & 230 & 50 & 3 & 4 & 6.569 & 5.527 \\
\hline 8 & 108 & 60 & 230 & 50 & 4 & 8 & 4.532 & 5.306 \\
\hline 9 & 108 & 60 & 230 & 50 & 5 & 12 & 3.913 & 6.645 \\
\hline 10 & 117 & 40 & 160 & 50 & 3 & 8 & 2.014 & 5.306 \\
\hline 11 & 117 & 40 & 160 & 50 & 4 & 12 & 2.525 & 3.994 \\
\hline 12 & 117 & 40 & 160 & 50 & 5 & 4 & 2.543 & 2.919 \\
\hline 13 & 117 & 50 & 230 & 10 & 3 & 8 & 2.205 & 2.283 \\
\hline 14 & 117 & 50 & 230 & 10 & 4 & 12 & 2.135 & 3.133 \\
\hline 15 & 117 & 50 & 230 & 10 & 5 & 4 & 0.859 & 1.236 \\
\hline 16 & 117 & 60 & 90 & 30 & 3 & 8 & 5.705 & 2.283 \\
\hline 17 & 117 & 60 & 90 & 30 & 4 & 12 & 3.873 & 3.133 \\
\hline 18 & 117 & 60 & 90 & 30 & 5 & 4 & 6.323 & 0.204 \\
\hline 19 & 126 & 40 & 230 & 30 & 3 & 12 & 2.400 & 5.527 \\
\hline 20 & 126 & 40 & 230 & 30 & 4 & 4 & 1.673 & 2.283 \\
\hline 21 & 126 & 40 & 230 & 30 & 5 & 8 & 1.390 & 5.527 \\
\hline 22 & 126 & 50 & 80 & 50 & 3 & 12 & 1.859 & 3.778 \\
\hline 23 & 126 & 50 & 90 & 50 & 4 & 4 & 3.115 & 0.821 \\
\hline 24 & 126 & 50 & 90 & 50 & 5 & 8 & 2.561 & 1.236 \\
\hline 25 & 126 & 60 & 160 & 10 & 3 & 12 & 0.395 & 2.495 \\
\hline 26 & 126 & 60 & 160 & 10 & 4 & 4 & 0.003 & 0.615 \\
\hline 27 & 126 & 60 & 160 & 10 & 5 & 8 & 0.440 & 2.072 \\
\hline
\end{tabular}

Table 5. Utility value of individual responses

\begin{tabular}{ccccccc}
\hline $\begin{array}{c}\text { Ex. } \\
\text { No. }\end{array}$ & SR & KW & Wi*SR & Wi*KW & $\begin{array}{c}\text { Utility } \\
\text { value }\end{array}$ & Order \\
\hline 1 & 6.154 & 5.527 & 3.212 & 2.642 & 5.854 & 3 \\
2 & 5.160 & 5.972 & 2.693 & 2.855 & 5.548 & 6 \\
3 & 3.635 & 7.781 & 1.897 & 3.719 & 5.617 & 5 \\
4 & 6.396 & 5.086 & 3.339 & 2.431 & 5.770 & 4 \\
5 & 6.058 & 5.972 & 3.162 & 2.855 & 6.017 & 2 \\
6 & 4.447 & 5.749 & 2.322 & 2.748 & 5.070 & 8 \\
7 & 6.569 & 5.527 & 3.429 & 2.642 & 6.071 & 1 \\
8 & 4.532 & 5.306 & 2.366 & 2.536 & 4.902 & 9 \\
9 & 3.913 & 6.645 & 2.043 & 3.176 & 5.219 & 7 \\
10 & 2.014 & 5.306 & 1.051 & 2.536 & 3.587 & 12 \\
11 & 2.525 & 3.994 & 1.318 & 1.909 & 3.227 & 16
\end{tabular}




\begin{tabular}{lllllll}
12 & 2.543 & 2.919 & 1.327 & 1.396 & 2.723 & 18 \\
13 & 2.205 & 2.283 & 1.151 & 1.091 & 2.242 & 20 \\
14 & 2.135 & 3.133 & 1.115 & 1.498 & 2.612 & 19 \\
15 & 0.859 & 1.236 & 0.448 & 0.591 & 1.039 & 26 \\
16 & 5.705 & 2.283 & 2.978 & 1.091 & 4.069 & 10 \\
17 & 3.873 & 3.133 & 2.022 & 1.498 & 3.519 & 13 \\
18 & 6.323 & 0.204 & 3.301 & 0.098 & 3.398 & 14 \\
19 & 2.400 & 5.527 & 1.253 & 2.642 & 3.895 & 11 \\
20 & 1.673 & 2.283 & 0.873 & 1.091 & 1.964 & 22 \\
21 & 1.390 & 5.527 & 0.726 & 2.642 & 3.368 & 15 \\
22 & 1.859 & 3.778 & 0.970 & 1.806 & 2.776 & 17 \\
23 & 3.115 & 0.821 & 1.626 & 0.393 & 2.018 & 21 \\
24 & 2.561 & 1.236 & 1.337 & 0.591 & 1.928 & 23 \\
25 & 0.395 & 2.495 & 0.206 & 1.192 & 1.398 & 24 \\
26 & 0.003 & 0.615 & 0.002 & 0.294 & 0.295 & 27 \\
27 & 0.440 & 2.072 & 0.230 & 0.991 & 1.220 & 25 \\
\hline
\end{tabular}

\section{Conclusions}

In this experimental study, the combined utility and SDV method is applied for the estimation of optimum machining parameters to minimize surface roughness and kerf width. The conclusions drawn from this study are as follows:

- Combined utility and SDV method is employed to select the optimum machining parameters in WEDM machining of Al6061/SiC/graphite with zinc coated brass wire electrode.

- From these observations, experiment number 7 has the best rank. The parameters corresponding to experiment run number 7 are pulse on time 108 units (Level1), pulse off time 60 units(Level3), peak current 230 units (Level3), gap set voltage 60 units (Level3), wire feed 3 units (Level 1) and wire tension 4 units (Level1).

- Standard Deviation (SDV) method is also employed to find the relative importance of surface roughness \& kerf width. The weight ratios are found to be 0.522 and 0.478 respectively.

- The optimum results are adopted in validation study and the results based on WEDM process responses can be effectively improved.

\section{References}

1. R. Snoeys, F. Staelens, W. Dekeyser, Ann. CIRP, 35/2, 467-480 (1986).

2. S.S. Mahapatra, A. Patnaik, J. Braz. Soc. Mech. Sci. \& Eng. 28(4), 422-429 (2006).

3. PK. Mishra, PK. Non-conventional machining processes (Narosa Publishing House, NewDelhi, 2002)

4. F. Klocke, M. Schwade, A. Klink, A. Kopp, Proc. Eng. 19, 190-195 (2011).

5. D. Shichun, C. Xuyang, W. Dongbo, W. Zhenlong, C. Guanxin, L. Yuan, Int. J. Mach. Tools \& Manuf. 49, 788-792 (2009).

6. H. Somekawa, T. Mukai, J Alloys Compd. 417, 209-213 (2006).

7. K. Ponappa, S. Aravindan, P. Rao, J. Ramkumar, M. Gupta, Int J Adv Manuf Technol. 46, 1035-1042 (2010).

8. A. Muniappan, C. Thiagarajan, S. Somasundaram, IJMME-IJENS. 16(5), 95-103 (2017).

9. Jinkai Xu, Rongxian Qiu, Kui Xia, Linshuai Zhang, Huadong $\mathrm{Yu}$, Proceedings of 2015 International Conference on Advanced Mechatronic Systems, Beijing, Chaina (2016).

10. Bijomathew, B.A. Benkim, J. Babu, Procedia Material Science. 5,1863-1872 (2014).

11. Bijaya Bijeta, Nayak Siba, Sankar Mahapatra, Procedia Eng. 97, 469-478 (2014).

12. Yogendra Kumar, Hari Singh, Procedia Materials Science. 5, 2142-2151 (2014). 